\title{
The educational proposal to support sustainable development and its impacts for rural education
}

\author{
Gilmara Maria de Almeida ${ }^{1 *}$; Maria Eduarda da Silva Souza ${ }^{2}$; Aldo José Irineu Filho ${ }^{3}$; Juliana \\ Georgia da Silva ${ }^{4}$; Pedro Eduardo Santos Silva ${ }^{5}$; Julia Graziele da Silva ${ }^{6}$; Tayna Guilherme Santiago \\ Moreira $^{7}$; Cleoneide Carvalho dos Santos ${ }^{8}$; Ione Teresinha Oliveira Leitão ${ }^{9}$; Edvaldo Pedro da Silva ${ }^{10}$; \\ Juceli Gomes de Queiroz ${ }^{11}$; Adla Polayne Barbosa da Silva ${ }^{12}$; José Augusto Ferreira Neto ${ }^{13}$; Marcos \\ Vinícius Alves da Silva ${ }^{14}$; Rute França de Almeida ${ }^{15}$ \\ 1 Postgraduate in Educational Processes and Education People Management at University Center of Vitória de Santo Antão - UNIVISA \\ 2- 7 Undergraduate degree in biological sciences at Federal University of Pernambuco, Academic Center of Vitória - UFPE/CAV. \\ 8 Postgraduate in Biology Teaching at Venda Nova do Imigrante Faculty - FAVENI \\ 9 - 10 Master's degree in Education from the Ibero-American University Foundation - FUNIBER \\ 11 - 12 Graduating in Biological Sciences at University Center of Vitória de Santo Antão -UNIVISA \\ 13 Undergraduate degree in biological sciences at Federal University of Pernambuco, Academic Center of Vitória - UFPE/CAV \\ 14 - 15 Postgraduate in Methodology of Teaching in Biological Sciences at Leonardo Da Vinci University Center - UNIASSELVI
}

E-mail adresses: gilmara98@hotmail.com (Gilmara Maria de Almeida), dudasouzaa215@gmail.com (Maria Eduarda da Silva Souza), aldojfilho12@gmail.com (Aldo José Irineu Filho), juliana.georgia@ufpe.br (Juliana Georgia da Silva), Pedroeduardo942@gmail.com (Pedro Eduardo Santos Silva), julia.graziele@ufpe.br (Júlia Graziele da Silva), Taynam652@gmail.com (Tayna Guilherme Santiago Moreira), cleoneidecarvalho20@gmail.com (Cleoneide Carvalho dos Santos), ione.teresinhaL@gmail.com (Ione Teresinha Oliveira Leitão), edvalpe@yahoo.com.br (Edvaldo Pedro da Silva), Juceligomes1995@gmail.com (Juceli Gomes de Queiroz), adlapbs@gmail.com (Adla Polayne Barbosa da Silva), netodestak1998@gmail.com (José Augusto Ferreira Neto), vinicius201653@gmail.com (Marcos Vinícius Alves Da Silva ), francarute95@gmail.com (Rute França de Almeida)

${ }^{*}$ Corresponding author

\section{To cite this article:}

Almeida, G. M.; Souza, M.E.S.; Filho, A.J.I.; Silva, J.G.; Silva, P.E.S.; Silva, J.G.; Moreira, T.G.S.; Santos, C.C.; Leitão, I.T.O.; Silva, E.P.; Queiroz, J.G.; Silva, A.P.B.; Neto, J.A.F..; Silva, M.V.A.; Almeida, R.F. The educational proposal to support sustainable development and its impacts for rural education. International Journal of Sciences. Vol. 2, No. 3, 2021, pp. 14-18. ISSN 2763-5392.

Received: 10 07, 2021; Accepted: 10 08, 2021; Published: 11 03, 2021

\begin{abstract}
Field education has become a national public policy built and defended by social movements. In this process of recognition several experiences were being implemented by the states and municipalities, such as the experience of the Landless Movement (MST), Agricultural Family Schools, Active School and the Basic Education Movement. Based on these, we seek to analyze the contribution of the educational proposal to support sustainable development for the implementation of the field education policy at the local level. The study will be based on bibliographical research from the theorists ARROYO, CALDART, MOLINA, MANÇANO, MOURA and SOUZA, making analysis specifically of the booklet "Multiple Looks of a Pedagogical Walk" systematization of the experience experienced in the municipalities of Vicência, Pombos and Orobó. In this sense, we took the Educational Proposal to Support Sustainable Development (PEADS) for analysis, with regard to theoretical bases and philosophical principles. We want to understand how this proposal has been impacting and influencing the education of the field at the local level, therefore, we consider that the education of the field is part of the need to have an educational policy that turns to the specificities of the peoples of the field, valuing and enhancing their cultures.
\end{abstract}

Keywords: Field education. PEADS. Educational Policy 
2 Almeida, G. M.; Souza, M.E.S.; Filho, A.J.I.; Silva, J.G.; Silva, P.E.S.; Silva, J.G.; Moreira, T.G.S.; Santos, C.C.; Leitão, I.T.O.; Silva,

E.P.; Queiroz, J.G.; Silva, A.P.B.; Neto, J.A.F..; Silva, M.V.A.; Almeida, R.F. The educational proposal to support sustainable development and its impacts for rural education...

\section{Introduction}

The education of the countryside has not attended as the rural environment should, because there is a curriculum focused on training in cities. In this same context, the potentialities of this medium are not valued, that is, there is a lack of chance with the schools of the countryside. We can perceive this when we look at the textbooks, the very methodology of the classes; these aspects do not differ from those of the City; the school does not take into account the realities experienced by the students, however, they do not care about the personal, social and economic developments of that environment (SOUZA, 2006).

We have a great impasse in our society to keep young people or families in rural areas, because it is devalued and not be able to envision improvement of life, this is culturally built and the school reinforces this reading of the world, however we have a rural environment decadent of educational, agricultural, social and health policies that actually meet the real needs of this public (MANÇANO, 1999).

The training of teachers in the field education is one of the lines of action of the Alternative Technology Service SERTA, from the projects developed by the institution in this area, there was an interest in researching and analyzing the impacts of this proposal on field education. Issues such as these have been addressed through studies, together with some social movements that preach a pedagogy or methodology of education of the field enhancing the rural environment, enabling it to be a means that can be sustainable, avoiding the rural exodus (ARROYO, 2008).

This article aims to analyze the contribution of the educational proposal to support sustainable development for the implementation of the field education policy at the local level. Its main discussion will be focused on the reflection of the proposal as a methodology of field education, considering the aspects of social, cultural, political and didactic influence in educational practice.

For PEADS, the experience of teaching and learning should be considered as a collective construction, teacher and student learn and teach considering that the school must articulate the didactic contents with the daily life of the students. This discussion is part of Freirean pedagogy when it turned to the defense of liberating education from reality (SOUZA, 2006).

\section{Methodology}

This is a study with data collection from secondary sources, through a bibliographic survey and based on the experience experienced by the authors at the time of an integrative review. For the survey of articles in the literature, a search was conducted in the following databases: Latin American and Caribbean Literature on Health Sciences (LILACS), PubMed and Scientific Electronic Library Online (SciELO).

\section{Results and Discussion}

\subsection{The fight for a country education policy}

The main discussion presented here will be to realize the challenge we have about the education offered to the rural environment, and what conception of education is contained in this offer. This education needs to be differentiated in order to meet the realities of the peoples of the countryside, but, above all, it needs to be educated in the broader sense of the process of human formation, as Arroyo (2008, p. 78) states:

The education of the Countryside values the human being. By valuing the human, the proposal of field education emphasizes training; appreciation; transformation of the human person in all its dimensions, education for social transformation, for service, for production, culture, cooperation, education as a process of formation, education of the people made by the people, agent of their own education.

Schooling is a fundamental social right to be guaranteed for every citizen, although it is still disrespected both in the countryside and in the city, but we can consider that today schooling is experiencing a moment of great importance as never before discussed.

The rural environment has always been considered a place of poor people, without culture, backward, in this context the rural exodus emerges with great force, people went after better living conditions in the cities and discredited the countryside, the school and the teacher reinforced this idea. Today, we have to build a field education project that contributes to the reality of the field, thinking about family agriculture as a work initiative, production and sustainability, in the perspective of demystifying this thought that according to Souza (2006, p.12) critical:

Do you see these as backward, unproductive, endangered so you can spend money, building schools, expanding grades, qualifying teachers? Why fix children and adolescents and young people in forms of production condemned to extinction?

All this leads us to understand the organization of the various movements in claiming and proposing a quality Educational Public Education which has been the reason for large manifestations organized by various social movements, the work developed in many municipalities are initiatives that demonstrate the existence of an accumulation of experiences that cannot be over considered at the time of defining field education policies. It is from this set that we have recreated the meaning of the field, Country Education and its subjects. A Public Policy of Field Education must respect all forms and modalities of education that are guided by the existence of the field as a space of life and lived relationships, because it considers the field as a space that is both a product and producer of culture. It is this capacity that 
produces culture that constitutes it as a space for the creation of the new and the creative and not, when merely reduced to the space of economic production, as the place of delay, of non-culture.

In order to consider these statements, we need to be clear about the social place that education can occupy in the construction of a development project, it is worth noting that education alone will not solve so many social problems, but it can be a very important element if combined with a set of political, economic and cultural actions.

We are understanding by school of the field that works from the interests, politics, culture, and economy of the various groups of workers and workers of the field, in their various forms of work and organization, in its dimension of permanent process, producing values, knowledge and technologies from the perspective of the egalitarian social and economic development of this population.

Continuing education is one of the processes of fundamental importance, because it is in it that the teacher is the subject of his activities contextualizing and recontextualizing, having as a starting point his beliefs, attitudes, values and ideas. These points need to be well worked out so that we can ensure a teaching staff capable of considering and defending the ideals and values of the peoples of the field.

In this context we cannot keep the idea of having in the field teachers who did not give expected results in the city, who did not interact with the school community or who did not vote for the current mayor and as punishments will work in the rural environment, we should consider what Mançano points out $(2008, \mathrm{p} 137)$ when he says that the system should "provide the School of the Field, coordinators and teachers who do know and commit to the reality of the field."

From these analyses is where we point out that there are many educators unprepared and without identification with the environment, bumping into the methodology and pedagogical knowledge, for this purpose this continued training provides the educator with a broader conception of education of the field in the theoretical and pedagogical practice, which does not give is to repeat what criticizes Moura (2003, p. 78) " itis in school that we find a lot of mechanical repetition, a sameness in techniques, dynamics, ways of teaching and learning".

It is in this process of action-reflection-action that professional knowledge develops. Without continued training, teaching will be compromised. For quality education is tied to the constant practice of study and research.

From these contexts experienced by the different individuals who represent the field, through the Chamber of Basic Education of the National Council of Education in 2001, the opinion is approved, supporting the "Operational Guidelines for field schools", provoked by Article 28 of the LDB and by the various social movements of the field that propose measures to adapt the school to the life of the field, considering it as a heterogeneous space, of economic diversity, multiculturalism and demands for basic education.
This opinion meets the demands of society, as well as provides subsidies for the development of pedagogical proposals that contemplate such diversities. This process only validated what the Alternative Technology Service had already begun to do with the schools of the field since the 90s, through the Educational Proposal to Support Sustainable Development, this methodology has the principles of popular education and values all diversity of the field.

\subsection{Being and being in the field through school}

In order to understand the impacts of PEADS for field education, we conducted bibliographic research in the area, based on the Principles and Foundations of the Educational Proposal to Support Sustainable Development, specifically Serta as an anchor institution of the process. As well as, and the Operational Guidelines for Basic Education in Rural Schools, in order to realize an interface between PEADS and the national policy of education of the field.

To analyze the contribution of PEADS in the municipalities of Vicência, Pombos and Orobó, we analyzed the systematization of this experience, explained in the booklet "Multiple Looks of a Pedagogical Walk".

SERTA, a non-governmental institution classified as a civil society organization of public interest, OSCIP, which was founded in 1989 by a group of farmers, technicians and educators who participated in the Center for Training and Monitoring alternative projects (CECAPAS), then based in Pesqueira (PE) and linked to the National Conference of Bishops of the Northeast, has as its mission to "train young people, educators and family producers to act in the transformation of their circumstances and in promoting the sustainable development of the field".

Since its origin, it has focused on the development and recognition of the importance of family farming. Throughout its twenty years of activity, from the perspective of justice and social inclusion, SERTA developed the PEADS methodology - Educational Proposal to Support Sustainable Development today, recognized for the positive impacts on the training, mobilization and organization of emerging social actors committed to the development of the field and the strengthening of family agriculture.

At the invitation of CONTAG - Confederation of Agricultural Workers, SERTA participated intensely in the construction of operational guidelines for basic education in rural schools, approved by the National Council of Education and in the process of implementation by municipalities, states and MEC.

He made a systematic contribution in development education, together with the national movement in defense of the country school, for understanding the country schools (so-called rural) as a privileged space for learning and social emancipation of the rural populations. Through projects such as "Learning Life in the Semi-arid", "Educating Program", Minor HDI, "Knowledge of the Earth" SERTA spread the PEADS - Educational Proposal to Support Sustainable Development, training teachers of rural schools in about 48 
4 Almeida, G. M.; Souza, M.E.S.; Filho, A.J.I.; Silva, J.G.; Silva, P.E.S.; Silva, J.G.; Moreira, T.G.S.; Santos, C.C.; Leitão, I.T.O.; Silva,

E.P.; Queiroz, J.G.; Silva, A.P.B.; Neto, J.A.F..; Silva, M.V.A.; Almeida, R.F. The educational proposal to support sustainable development and its impacts for rural education...

municipalities located in the Sertão do Cariri (PB), in the Sertão do Pajeú (PE), in the middle of São Francisco, in the Southern Agreste and in the Glória de Goitá. (1.Parnamirim, 2.Lagoa Grande, 3.Jatobá, 4.Floresta, 5.Santa Maria de Boa Vista, 6.Carnaubeira da Penha, 7.Salgueiro, 8.Petrolândia, 9.Itacuruba, 10.Tacaratu, 11.Orocó, 12.Ibimirim, 13.Cabrobó, 14.Belém de São Francisco, 15.Ouricuri, 16.Trindade, 17.Araripina, 18.Petrolina, 19.Juazeiro, 20.Serra Talhada, 21.Paulo Afonso, 22.Feira de Santana, 23.Campina Grande, 24.Tupanatinga, 25.Iati, 26.Itaíba, 27.Inajá, 28.Águas Belas, 29.Paranatama, 30.Manari, 31.Saloá, 32.Terezinha, 33.Iguaracy, 34.Quixaba, 35.São José do Egito, 36.Sertânia, 37.Tuparetama, 38.Camalaú, 39.Monteiro, 40.Prata, 41.São Sebastião do Umbuzeiro, 42.Soledade, 43.Sumé, 44.Lagoa de Itaenga, 45.Pombos, 46. Chã de Alegria, 47.Vicência and 48.Orobó).

The choice of SERTA as a field of study occurred through the recognition of the work presented by the various actors involved in these various municipalities and by the contribution in the field education, when we knew SERTA as an educational institution of the third sector had to identify also its methodological proposal that guides its formative processes, called Educational Proposal to support Sustainable Development - PEADS, which has its theoretical and philosophical principles based on popular education, with religious influence through the method: seeing, judging and acting created by Cardin. In fact, its originality is not easy to explain, because its construction was based on several currents that defend popular education and the Countryside.

PEADS is a procedural methodology that provides the involved to discover, build, experience, intervene, for this it is constituted by sequential and contextualized stages, the first stage is the research for realizing that the school needs to know and approach reality, data are collected and ordered, part of observation to diagnosis. The research - knowing, seeing, raising information, observing, registering, socializing - is the first approximation that students make from themes (agricultural, environmental and population censuses, etc.), organized as pedagogical records and with the objective of contributing to the construction and production of knowledge of the community and school, constituting the instrument for elaboration and re-elaboration of thought, of reasoning. Thus, research is not only a tool for the construction of knowledge, but also a posture towards the reality where students and educators assume a critical sense, curiosity and "reconstructive questioning", enabling teachers to discover, explore, involve their students in situations problems of their context, so that they are instigated to carry out research as an instrument of investigation and search for knowledge.

Therefore, "involving students in research activities, in knowledge projects" is a competence that should be developed in the classroom (MOURA, 2003).

In the procedural sequence of the proposal the second stage is the deepening and development (unfolding) of data analysis, from elevation to a more scientific level, which requires experimentation, verification and articulation with modern sciences and other forms of knowledge. In this stage, the educator gathers, thematizes, adds, enriches, unfolds the knowledge acquired in the first stage in its contents (cultural knowledge and values), through the various areas of knowledge, including conventional disciplines (Mathematics, Portuguese, History, Geography, Sciences, Art and others) and transversal themes.

This strategy is based on inter-dimensionality where the construction of knowledge is seen in an integrated way including values, knowledge, attitudes, technologies, work, environment, the relations between local and global. The activities most used in this strategy aim to organize, sort and systematize the data to be deepened: calculations, tables, graphs, spreadsheets, scripts, texts, drawings, theater, poetry, singing, reading, writing and further research with a deeper dimension.

After having researched and analyzed the data, the third stage is that of the intervention is realized through the return of the diagnosis, constructed in the first strategy to the social actors involved, serving as a tool of a new knowledge that, analyzed, helps as a mobilizing instrument and defines which aspects of the reality studied the school and the community can intervene. At that moment the collected data are presented in a more elaborate and synthetic way in plenary sessions, community meetings, with the participation of interested persons. This stage strengthens the principle of explaining the role of the school in the construction of the alternative project for the development of education. Without this, initiatives to improve education risk remaining on the surface, in the media and not in the ends. At this moment it is also sought to aggregate artistic and cultural elements, and explore them through emotions and feelings, whether in the form of theater, singing, with sound resources, plastics, to help in the provocation of new actions, in the awareness and mobilization of communities and organized groups. The activities of this strategy also aim to guide the referral of mobilizing actions to solve problems and strengthen the better appropriation of existing potentials on site, with planning and distribution of responsibilities: "what to do, why and for what, when, how, who and with whom, by how much?".

Considered the last and at the same time present in all others, the fourth stage is the evaluation of the whole process, allowing the return to pedagogical practice with more experience, theory and depth. The objects of the evaluation are the procedures, coordination, contents, learning, results, instruments used and means.

According to MOURA, the instruments used do not disregard the traditional practices of evaluating, but are used as didactic and pedagogical resources, oral and written texts, group work, experience report, activity report, testimonials, gymkhana, games, project elaboration, reportage, poetry, parody, drawing, graphic and dramatization among others. Assuming that evaluation is a process that enables the strengthening and redirection of actions, it is important to highlight that PEADS allows the work of the role of all social 
actors of the communities that become co-authors and coexecutors and partners of actions revealing attitudes, values and skills that contribute to the social transformation and achievement of the objectives of this proposal.

\subsection{A new call for a new methodology}

Educators were challenged to change a classroom experience for decades, with the community stopped, stagnant, skeptical by circumstances, PEADS forces the actors involved to get out of inertia, to think, question and get involved. Here's what drives country education: involvement.

In PEADS, the learning teaching process considers that students need to learn to read reality and know it in order to be able to rewrite and transform it, transform reality as a subject of history itself. Learning is a creative discovery, because teaching one learns and learning is taught. The search for alternatives and proposals should be a constant in our daily life, in the sense of rescuing the "man", the "citizen" and the "worker" from his exercise of citizenship and his dignity.

For education professionals engaged in the educational proposal for development to Sustainable Support - PEADS. This proposal is being of great importance for the Field Schools, for the development of student learning, in the interaction of the school - community where they are gradually taking a new direction, the pleasant and constructive classes, associating curriculum, reality and world reading. Plan as a group building collectively, all contributing to the improvement and success by a quality education in the field.

The research work takes place inside and outside the school where everyone participates in the investigative action, talking and visiting families, to understand the issues under discussion, and thus gradually overcome obstacles and overcome challenges.

Reconstructing history, believing in potential, changing behavior regarding life in the field is not an easy task for educators, challenges are constant, changes of opinion in the face of each obstacle go hand in hand, because it is a slowresult job, since PEADS invites students and educators to think, to question and seek solutions that have a collective benefit, listening, opining and socializing knowledge.

Teachers begin to value the field in its specificity, using nature as a potential to build and produce a vision of growth and development of this environment.

The experience experienced by the municipalities of Vicência, Pombos and Orobó, from the systematization, points out that the results obtained during the performance of PEADS in each municipality are presented with different nuances, due to the time of its implementation and implementation, portray changes and paradigm breaks in the various areas of the municipal structure, which makes it possible to understand education as a fundamental social policy for sustainable development. It also points out some challenges brought by those involved in thinking about the continuity of the proposal, even if there are changes in the government in the legislative and executive sphere. One of the most relevant contributions were the processes of continuing education with teachers and pedagogical coordination that together reconstructed their practices and conceptions, providing students with a new way of thinking and being in the field.

\section{Conclusions}

PEADS has been contributing in the pedagogical practice and in the lives of the actors involved in this construction of a new model of education for the peoples of the field, in this perspective it is of fundamental importance to understand that the proposal is not disjointed, it was from the experiences and articulation with the social movements of the class that gave rise and life of this new educational project, experienced only by the municipalities that understands the importance of prioritizing the education of the field as well as the philosophical and ideological principles of PEADS.

From these political struggles, the municipalities are organizing themselves to meet this demand, but there is no single model and ready to be applied in the schools of the field, however the choice of PEADS is based on institutional recognition and the various contributions in the moments of discussions and validation of the field education policy, from the local to the national sphere.

All this political struggle is to project a paradigm shift, in the sense of recognizing one another as a subject of the field and for the field, claiming for a quality education respecting the singularities and peculiarities. And for this to happen, there must be collective work, equality, autonomy, participation and humanization, pillars that underpower, strengthen and promote the development of educational practice. Field Education should therefore be a means of training that has the commitment to recognize the subjects, rescuing and valuing their identity as a field worker, based on the root of culture, knowledge and experience within their social space.

In PEADS, education does not only excel in conceptual, formal knowledge, or to pass on elementary or basic knowledge, claiming that in the field learning knowledge that develops its intellectual capacity will not make a difference, so there is no need for those who deal in the garden. On the contrary, it treats conceptual knowledge as a necessity to remain in its space, so for this to happen in fact is that the constituted, governmental and non-governmental authorities direct their gaze to this cause.

Field Education is a fundamental condition for the exercise of citizenship of the peoples of the countryside, with the right to an education in its place and with its participation, its culture and its human and social needs. An education that leads us to act in the conservation of nature, to understand how to live with it and in it. An education that allows us to live with responsibility and commitment, individually and collectively, where everyone who is on board this great 
6 Almeida, G. M.; Souza, M.E.S.; Filho, A.J.I.; Silva, J.G.; Silva, P.E.S.; Silva, J.G.; Moreira, T.G.S.; Santos, C.C.; Leitão, I.T.O.; Silva, E.P.; Queiroz, J.G.; Silva, A.P.B.; Neto, J.A.F..; Silva, M.V.A.; Almeida, R.F. The educational proposal to support sustainable development and its impacts for rural education...

spaceship are very important pieces of the gear that transforms man and makes a difference in his surroundings.

It is in this context of understanding these philosophical and ideological conceptions, that we recognize how much PEADS has contributed and helping to strengthen both pedagogical practice and the thinking of the policy of the field education movement, from the local to the global sphere.

\section{References}

[1] ARROYO, Miguel Gonzáles, CALDART, Roseli Salete, MOLINA, Mônica Castagna. (organizadores) Por uma Educação do campo, Petrópolis/RJ: Vozes. 2008.

[2] MANÇANO, Fernandes Bernardo. Por uma Educação Básica no Campo. A educação Básica e o Movimento Social do Campo. RJ: Vozes. 1999.

[3] MOURA, Abdalaziz de. (Org.) Princípios e fundamentação da Proposta de Apoio Ao desenvolvimento Sustentável - Peads: Uma proposta que revoluciona o papel da escola diante das pessoas, da sociedade e do mundo. Glória do Goitá: PE, 2003.

[4] SOUZA, Maria Antonia de. Educação do Campo: Propostas e Práticas pedagógicas do MST, Petrópolis, RJ: Vozes, 2006. 